\title{
Reading Comprehension Monitoring in School-aged Children with Language Impairment
}

\author{
Minyoung Park, Hyojin Yoon \\ Department of Speech-Language Pathology, Chosun University, Gwangju, Korea
}

Correspondence: Hyojin Yoon, $\mathrm{PhD}$ Department of Speech-Language Pathology, Chosun University, 309 Philmun-daero, Dong-gu, Gwangju 61452, Korea

Tel: + 82-62-230-7462

Fax: +82-608-5392

E-mail: hyoon@chosun.ac.kr

Received: October 20, 2020

Revised: November 15, 2020

Accepted: November 15, 2020

This paper is based on the master's thesis of the first author.

This study was supported by research fund from Chosun University (2020).

\begin{abstract}
Objectives: This study investigated reading comprehension monitoring in school-aged children with language impairment (LI). Reading comprehension monitoring was measured using error detection and correction tasks. Error types included lexical inconsistency, external inconsistency, internal inconsistency which is violating prior knowledge, and internal inconsistency within the text itself. Methods: Fifteen children with LI between Grade 3 and 5 and 15 grade-matched typically developing children participated. A total of 30 participants read 3 stories that contained 3 types of errors and performed error detection and error correction tasks. Results: Children with LI showed difficulty both in detection tasks and correction tasks compared to typically developing children. When looking at the performance of each task error type, both groups found the external inconsistency type best in the detection task, followed by the vocabulary and internal inconsistency error type. In the correction task, external inconsistency error types were best corrected, followed by internal inconsistency and vocabulary. Also, it was found that the total reading comprehension monitoring score and lexical inconsistency error type were related to reading comprehension for children with $\mathrm{LI}$, while total reading comprehension monitoring scores and internal inconsistency error type were related to reading comprehension for typically developing children. Conclusion: School-aged children with $\mathrm{LI}$ were found to have difficulty in reading comprehension monitoring compared to typically developing children, especially in finding errors rather than in correcting errors. This finding suggested that problems in reading comprehension monitoring for school-aged children with $\mathrm{LI}$ would be likely to negatively influence reading comprehension.
\end{abstract}

Keywords: School-aged children with LI, Reading comprehension monitoring, Error detection task, Error correction task, Reading comprehension
학교에 입학하면서 아동들은 본격적으로 읽기 및 쓰기 교육에 노출이 되고, 읽기를 통해 새로운 정보를 얻음으로써 개인의 지식 과 언어 능력을 확장시키기 때문에 읽기 능력은 학령기 아동에게 중요한 학습의 목표이자 수단이 된다. 언어발달의 어려움을 경험하 는 언어장애 아동은 학령기에 읽기 어려움도 동반할 가능성이 높 다(Werfel \& Krimm, 2017). 본 연구에서는 단어 읽기가 자동화되 고 학습을 위한 읽기를 하는 단계인 초등 3-5학년 언어장애 아동 을 대상으로 읽기이해에 영향을 미치는 요인으로 밝혀진 이해 모니 터링 능력을 살펴보고 이를 통해 읽기이해 어려움의 특성을 살펴 보고자하였다.
읽기의 궁극적인 목적은 읽은 내용을 이해하는 것이다. 읽은 것 을 이해하는 것은 읽은 내용에 대한 정신 표상(mental representation)을 구축하는 것이며, 이를 위해 여러 단계에서 다양한 요인들 이 관여한다. 구체적으로 살펴보면, 우선 쓰여진 단어를 시각적으 로 확인하고, 단어의 음운론적, 철자적, 의미론적 표상에 접근하고, 구문적 특성을 파악하여 각 문장의 의미를 파악하는 과정이 일차 적으로 필요하다. 뿐만 아니라 자신의 배경지식을 텍스트의 의미와 결합하고, 글에 명시되지 않은 정보는 추론 과정을 통해 정신 표상 에 포함하는 과정도 포함한다. 이 과정을 통해 주어진 텍스트에 대 한 긴밀하고 응집성 있는 표상을 형성할 수 있게 된다. 그래서 잘 읽 
고 이해한다는 것은 이러한 표상의 산물이라고 할 수 있다. 이 표상 과정과 이해의 산물을 설명하는 대표적 모델은 Kintsch (1998)의 통합-구성 모델(construction-integration model)인데, 이 모델은 여러 단계를 거쳐 정신 표상이 형성된다고 설명한다. 구체적으로 살펴보면, 첫 단계는 개별적 어휘와 각 문장의 구문적 특성에 대한 표면적 수준(surface level)에서의 표상이다. 두 번째는 담화 수준 (text-base)으로 개별적인 문장이 아니라 각 문장들 간의 정보를 유 기적이며 응집력 있고 정확한 정보로 표상하는 과정으로, 이 과정 내에서 추론 능력과 이미 들어온 정보와 새롭게 들어오는 정보를 통합하면서 자신의 이해 정도를 점검하는 이해 모니터링(comprehension monitoring) 능력 등이 필요하다. 마지막 단계인 상황 모델 (situation model)은 좀 더 정교화된 표상으로 독자의 배경지식과 경험, 읽기의 목적과 동기 등에 대한 통합과 관련된다.

단어와 문장 수준의 읽기이해가 가능한 아동도 추론이나 이해 모니터링 등의 상위인지 전략을 사용하는 데 어려움이 있다면 읽기 이해의 어려움을 경험할 수 있다(Kim \& Kim, 2014, Oakhill, Hartt, \& Samols, 2005). 추론이나 이해 모니터링과 같은 상위인지 전략은 통합 구성 모델의 두 번째 단계인 담화 수준의 이해에서 반 드시 필요한 전략으로, 자기 자신의 인지 과정에 관한 지식과 통제 (Flavell, 1979)를 의미하는 것이다. 읽기 과정에서 필요한 상위인지 능력은 글을 읽다가 어려운 어휘나 빠진 정보를 발견했을 때 추론 전략을 통해 확인하거나 이전에 들어온 정보와 새롭게 들어온 정 보를 통합하고, 자신의 이해 정도를 점검하는 등의 다양한 전략을 자발적으로 사용할 수 있는 능력이다(Kim \& Kim, 2014). 특히, 이 러한 전략들 중 읽기이해 모니터링은 자신의 이해 정도를 의식적으 로 확인하고 조절하는 과정으로 읽기이해를 위해 반드시 필요한 전 략이다(Baker, 1984; Kim, 2014; Kim \& Kim, 2006; Oakhill et al., 2005).

이해 모니터링은 구어이해와 읽기이해 모두에서 사용하는 전략 이다. 대화상황에서는 청자는 화자가 산출한 발화의 의미를 이해 하지 못했을 때 의사소통의 실패를 확인하고 화자에게 명료화 요 구하기를 통해 구어이해 모니터링 전략을 사용한다. 읽기에서는 독 자가 글을 읽는 동안 이해를 어렵게 하는 부분이 생겼을 때 자신이 잘못 읽거나 놓친 부분을 이해하기 위해 글의 앞으로 되돌아가서 다시 읽을 수도 있고, 이해를 어렵게 하는 부분이 생소한 단어일 경 우에는 단어의 의미를 파악하기 위해 다른 참조물을 찾아보는 등 의 전략을 사용하는 것을 말한다(Oakhill, Cain, \& Elbro, 2014).

Paris와 Myers (1981)는 이해 모니터링의 과정을 3단계로 구분하 여 설명하였는데, 첫 단계는 자신의 이해 정도를 확인하는 평가 단 계(evaluation), 이해의 어려움을 인지한 후에 적절한 이해 전략을
선택하는 계획 단계(planning), 그리고 마지막 단계는 선택한 전략 을 적절하게 사용하여 이해를 가능하게 하는 조정 단계(regulation)이다. 즉, 독자는 글을 읽다가 이해를 방해하는 부분을 인식하 는 것이 필요하다. 인식한 후에는 이해가 되지 않은 부분을 이해 가 능하도록 하기 위해서 앞뒤 맥락을 통해 어휘의 의미를 추론하거 나, 앞으로 되돌아가서 다시 읽는 등의 적절한 전략을 선택하고 사 용해야 한다. 하지만 이 중 어느 하나라도 어려움이 있다면 읽기이 해는 실패할 가능성이 생기게 된다.

연구자들은 글에 의도적으로 오류를 포함시켜 제시한 뒤 이를 독자가 확인하고 글의 맥락에 맞게 수정할 수 있는지를 통해 이해 모니터링 능력을 살펴보고, 이를 읽기이해의 어려움과 관련 지어 설명하고자 하였다. 대표적으로 Baker (1984)는 5, 7, 9세 아동을 대 상으로 연구를 진행하였다. 글의 의미가 적절하지 않도록 어휘 비 일관성 오류(lexical inconsistency error)와 외적 비일관성 오류(external inconsistency error), 그리고 내적 비일관성 오류(internal inconsistency error)를 글에 포함하여 이를 통해 이해 모니터링 능 력을 살펴보았다. 어휘 비일관성 오류는 글에 포함된 비단어를 의 미하며, 외적 비일관성 오류는 자신의 배경지식에 반하는 오류이 며, 마지막 내적 비일관성 오류는 이전에 나온 내용과 뒤에 나온 내 용이 일치하지 않는 오류이다. 연구결과, 아동들은 어휘 비일관성 오류와 외적 비일관성 오류는 잘 찾을 수 있었으나 내적 비일관성 오류를 확인하는 것은 어려운 것으로 나타났다. 이는 어휘 비일관 성 오류와 외적 비일관성 오류는 아동의 어휘집 내에 있는 어휘의 정보를 확인하는 단순한 처리 과정인 반면, 내적 비일관성 오류를 확인하기 위해서는 이전에 읽은 내용을 기억하고, 지속적으로 들 어오는 정보들을 통합하고, 비교 분석하는 복잡한 인지처리 과정 을 거쳐야 하기 때문에 더 어려움을 보인 것으로 해석할 수 있을 것 이다. 즉, 글을 읽는 동안 모르는 어휘가 나타났을 때에는 비교적 쉽 게 앞 뒤 문맥을 통해 잘 유추할 수 있는 반면 글의 앞 부분과 뒷 부 분을 통합하는 것은 좀 더 어려울 수 있다고 설명할 수 있을 것이다. 또한 이 과정에서 하나라도 어려움을 경험한다면 읽기이해는 실패 할 수 밖에 없을 것이다.

언어장애 아동의 읽기이해 모니터링을 살펴본 연구들은 제한적 이지만, 언어장애 아동을 대상으로 하여 구어이해 모니터링을 살 펴본 연구들에 따르면, 언어장애 아동은 구어이해 모니터링 과제에 서 어려움을 보이는 것으로 나타났다. Jeong (2010)의 연구에서는 초등 4학년 언어장애 아동과 학년을 일치시킨 일반 아동을 대상으 로 오류가 포함된 이야기를 들려준 후 이야기 속에 포함된 오류를 찾을 수 있는지에 대한 확인 과제와 그 오류가 왜 이상했는지 설명 하는 수정 과제를 실시하였다. 연구결과 언어장애 아동은 오류를 
확인하고 수정하는 과제 모두에서 일반 아동보다 수행력이 낮은 것 으로 나타났다. 연구자는 언어장애 아동의 낮은 수행력을 자신의 이해 정도를 지속적으로 점검하는 이해 모니터링 능력과 추론 능력 의 어려움으로 설명하였다.

본 연구에서 다루고자 하는 읽기이해 모니터링 능력은 대부분 읽기부진 아동들을 대상으로 연구되어 왔다(Kim, 2014; Kim \& Kim, 2006; Oakhill et al., 2005; Paris, \& Oka, 1989). Oakhill 등 (2005)은 읽기이해부진 아동과 읽기이해 능력이 정상적으로 발달 하는 10 세 아동을 대상으로 읽기이해 능력을 살펴보았을 때, 일반 아동의 읽기이해 모니터링 수행력이 높게 나타났다고 보고하였다. 또한 읽기이해 능력에 대한 예측연구를 한 Kim (2014)의 연구에 따 르면, 읽기저성취 아동 집단에서는 어휘와 읽기유창성을 통제한 후 에도 읽기이해 모니터링 능력이 여전히 읽기이해 능력을 예측하는 요인인 것으로 나타났다. 이러한 선행연구들을 통해 읽기이해 모니 터링 능력은 읽기이해의 어려움을 야기하는 다양한 요인 중 하나 라고 예측할 수 있을 것이다.

학령기 언어장애 아동의 읽기이해 능력을 살펴본 연구들은 읽기 이해의 어려움을 언어지식이나 추론 능력의 결함으로 종종 설명하 곤 하였다(Kim \& Kim, 2006; Bishop \& Adams, 1992; Catts, 1993). 하지만 여러 선행연구를 통해 읽기이해의 중요한 예측 요인 중 하나 로 간주하고 있는 이해 모니터링 능력에 대한 연구는 제한적이다. 따라서 본 연구에서는 학령기 언어장애 아동을 대상으로 하여 읽 기 과정동안 효율적인 이해 모니터링 전략을 사용하는지를 살펴보 고자 한다. 이해 모니터링 능력은 이야기 글에 의도적으로 오류를 포함하고, 이러한 오류를 찾을 수 있는지를 살펴보는 확인 과제와 글의 흐름에 맞도록 오류를 수정할 수 있는지를 살펴보는 수정 과 제로 살펴보았다. 오류 유형은 어휘 비일관성, 외적 비일관성, 그리 고 내적 비일관성 오류를 포함하였으며, 오류 유형에 따라 집단 간 에 어떠한 차이를 보이는지도 살펴보았다. 마지막으로 읽기이해 모 니터링과 읽기이해와의 상관분석을 실시함으로써 읽기이해 능력 과 읽기이해 모니터링 능력 간에 관련성을 고찰해 보고자 하였다.

\section{연구방법}

\section{연구대상}

Chall (1983)은 초등학교 저학년에서 고학년으로 넘어가는 시기 는 학습을 위한 읽기를 시작하는 단계로 글을 이해하고 추론하는 데 중요한 시기로 설명하였다. 이에 따라 본 연구에서는 초등 3-5학 년 시기의 언어장애 아동과 일반 아동을 대상으로 선정하여 연구 를 진행하였다. 초등학교 3-5학년의 언어장애 아동 15 명(3학년-7명,
4 학년-4명, 5 학년-4명)과 이 아동들의 생활연령과 학년을 일치시킨 아동 15 명, 총 30 명을 대상으로 하였다. 전체 대상자는 첫째, 한국 어 비언어 지능검사-II (Korean version of Comprehensive Test of Nonverbal Intelligence-second edition; Park, 2014)에서 지능지수 가 80 점 이상으로 지능이 정상이며, 둘째, 한국어 읽기검사(Korean Language-based Reading Assessment, KOLRA; Pae, Kim, Yoon, \& Jang, 2015)의 하위 검사인 해독검사에서 표준점수 70점 이상으로 해독에 어려움이 없는 아동으로, 셋째 주양육자 및 담임 교사로부터 감각적, 정서적 및 신경학적 문제가 없다고 보고받은 아동을 대상으로 하였다.

본 연구에서는 학령기 아동언어검사(Language Scale for Schoolaged Children, LSSC; Lee, Heo, \& Jang, 2015)에서 하위 검사 4개 를 선택하여 실시하였으며, 이에 근거하여 언어장애 아동과 일반 아동을 선정하였다. 언어장애 아동 집단은 4 개의 하위검사 중 3 개 이상에서 환산점수 7점 이하로 나온 아동을 선정하였으며, 일반 아 동 집단은 4 개의 검사 중 3 개 이상에서 환산점수 7점 초과로 언어 능력에는 어려움이 없는 아동을 선정하였다. 하위 4 개의 검사는 LSSC의 구인타당도 검정 결과에 근거하여 표현언어지수와 가장 상관관계가 높은 하위 검사 2 개(반의어 표현, 동의어 표현), 수용언 어지수와 가장 상관관계가 높은 하위 검사 2 개(단락듣기이해, 문법 오류 판단)이다.

두 집단의 생활연령, 비구어성 지능지수, 단어해독과 LSSC의 4개 의 하위 검사의 환산점수 합의 평균 결과는 Table 1 에 제시하였다.

\section{연구과제}

본 연구에서는 언어장애 아동의 읽기이해 모니터링 능력을 측정 하기 위해 연구자가 의도적으로 이야기글에 오류를 포함시키고, 아 동이 글을 읽은 후 오류를 확인하고 수정하는 과제를 실시하였다.

이야기의 친숙도가 읽기이해 모니터링에 영향을 미칠 수 있기 때 문에 국외동화책 "Pookins gets her way" (Leicester, 2015), "A boy, a dog, a frog, and a fried” (Mayer \& Mayer, 1992)와 인터넷 웹사이 트의 창작동화를 연구자가 번역하고 수정하여 이야기글을 구성하 였다. 어휘나 구문 길이는 읽기이해와 읽기이해 모니터링에 영향을 미칠 수 있는 요인이므로 본 연구에서는 이러한 요인이 미치는 영 향을 최소화하고자 하였다. 우선 의미적 난이도를 통제하기 위하 여 Kim (2003)의 ‘등급별 국어교육용 어휘’에서 1-3등급에 포함되 거나 국립국어원의 '초등학교 교과서 어휘 조사 연구'에 1-3학년에 나타나는 어휘가 이야기의 $95 \%$ 이상을 차지하도록 구성하였다. 또 한 세 이야기글의 문장 수는 26-27개로 평균 26.6문장이며, 평균 어 절 수는 256.3 으로 구문의 길이를 조절하였다. 
Table 1. Participants' characteristics

\begin{tabular}{|c|c|c|c|c|}
\hline & $\mathrm{LI}(\mathrm{N}=15)$ & $\mathrm{TD}(\mathrm{N}=15)$ & $t$ & $p$ \\
\hline Age (month) & $117.73(12.59)$ & $118.26(10.76)$ & -.125 & .902 \\
\hline CTONI-2ª (standard score) & $96.63(9.84)$ & $106.70(9.75)$ & $-2.81^{* *}$ & .009 \\
\hline Decoding of KOLRA ${ }^{b}$ (standard score) & $91.66(15.60)$ & $99.60(8.37)$ & -1.73 & .094 \\
\hline LSSC $^{c}$ (scaled score $\left.{ }^{d}\right)$ & $6.13(.90)$ & $10.13(1.26)$ & $-10.00^{* * *}$ & .000 \\
\hline
\end{tabular}

Values are presented as mean (SD).

${ }^{a}$ CTONI-2 = Korean Comprehensive Test of Nonverbal Intelligence-2 (Park, 2014), 'OLRA=Korean Language based Reading Assessment (Pae et al., 2015), ' LSSC=average scaled score of 4 subtests of the Language Scale for School-aged Children (LSSC; Lee et al., 2015), 'Scaled score=a mean of 10 and a standard deviation of 3.

$\mathrm{LI}=$ children with language impairment; $\mathrm{TD}=$ typically developing children.

${ }^{* *} p<.01,{ }^{* * *} p<.001$.

각 이야기글에 포함된 오류는 이해 모니터링 연구에서 빈번하게 사용하는 오류인 어휘(lexical), 외적(external), 그리고 내적(internal) 비일관성 오류(inconsistency error)를 포함하였다(Baker 1984; Garner \& Reis 1981). 어휘 비일관성 오류는 제시하는 글 속 에 비단어가 포함되는 오류이며, 외적 비일관성 오류는 독자가 가 지고 있는 배경지식에 어긋나는 정보를 삽입하는 것이다. 또한 내 적 비일관성 오류는 제시하는 글 속에 서로 불일치하는 정보가 포 함된 오류이다.

우선 어휘 비일관성 오류는 이야기 속에 3회 이상 포함되지 않는 명사 어휘를 선정한 후 이를 연구자가 제작한 비단어로 바꾸었다. 비단어는 성인 발화에서 자주 산출되는 $\mathrm{CV}$ 음절과 $\mathrm{VC}$ 음절의 부 적 산출 빈도를 제시한 Shin (2008)의 연구를 참고하여 누적 산출 비율이 하위 20-50\%에 위치하는 CV 혹은 VC 음절을 선택한 후 종성을 추가한 $\mathrm{CVC}$ 음절 8 개와 $\mathrm{VC}$ 음절 7 개를 선정한 후 이를 조 합하여 2음절 비단어 3 개, 3 음절 비단어 3 개 총 6 개의 비단어를 어 휘 비일관성 오류로 제작하였다(ex., 투깐, 지절몰 등). 외적 비일관 성 오류는 뚜렷한 의미적 속성을 가진 명사 어휘 6개를 이야기 속 에서 선정하였고, 아동이 가지고 있는 어휘에 대한 의미적 속성과 반대되는 명사 어휘로 바꾸었다. 예를 들어 "느릿느릿 거북이 같 아.”의 '거북이'를 “느릿느릿 토끼 같아.”로 바꾸었는데, 아동은 자 신이 가진 배경지식과 일치하지 않는다는 것을 인지하여 이러한 외 적 비일관성 오류를 찾을 수 있어야 한다. 마지막으로 내적 비일관 성 오류는 글 속에서 내용이 일치하지 않는 문장이며, 이야기의 내 용을 변하게 할 수 있는 명사(3개), 동사(2개), 형용사(1개)를 선정 하여 구성하였다. 예를 들면 '개구리를 잡으러 간 소년과 강아지'의 글에서 글의 앞 부분에 “소년은 개구리를 잡지 못하자”라고 소개한 후 뒷 부분에서 “소년은 그물에 갇힌 개구리에게 소리쳤습니다”라 고 제시함으로서 두 문장의 내용이 불일치하도록 하였다. 연구에 서 사용된 이야기글과 오류의 예시는 Appendix 1에 제시하였다. 각각의 오류 유형은 6 개씩 3 개의 글에 포함하여 총 오류의 수는 18
개이다.

아동이 글 속에 포함된 오류를 적절하게 확인하고 수정할 수 있 는지를 알아보기 위해 예비검사를 먼저 실시하였으며, 이때 연구과 제의 천정점이 나올 가능성을 배제하기 위해 초등 6 학년 아동 5 명 에게 실시하였다. 예비검사를 실시한 결과 $50 \%$ 이상의 아동이 찾 지 못하거나 수정하지 못한 오류들은 수정하였으며, 수정된 과제 를 다시 다른 6 학년 학생 5 명에게 재실시하였을 때 아동들은 $80 \%$ 이상 오류를 찾고수정할수 있었다.

이야기글에 포함된 어휘, 문법 및 구문이 3-5학년의 아동에게 적 절한지, 그리고 어휘, 외적, 내적 비일관성 오류가 적절한지에 대한 내용타당도는 언어병리학 교수 1 인과 언어재활사 경력 10 년 이상이 며 언어병리학 박사학위 소지자 2 인에게 의뢰하였다. 내용타당도 지수는 Likert 5점 척도(1점 ‘매우 타당하지 않다', 2점 ‘타당하지 않 다', 3점 ‘보통이다', 4점 ‘타당하다', 5점 '매우 타당하다’)로 실시하 였으며, 평균 내용타당도를 산출한 결과 4.538 이었다.

\section{연구절차}

본 연구는 조선대학교 생명윤리위원회의 승인을 받은 후에 진행 하였다. 검사는 아동이 다니는 초등학교나 언어치료실, 혹은 집 등 조용한 공간에서 검사자와 아동이 일대일로 실시하였다. 모든 연구 과제의 수행은 디지털 녹음기(R-O9HR, Roland Co.)로 녹음하여 대상자의 반응을 기록하고 채점하였다. 우선 대상자 선정을 위해 K-CTONI-2, KOLRA의 해독검사, LSSC 검사를 실시하였다. 그 후 본 연구과제인 읽기이해 모니터링 과제와 KOLRA의 읽기이해 검 사를 실시하였다.

본 연구에서는 이해 모니터링의 평가 과정을 살펴보기 위한 오류 확인 과제와 조정 과정을 살펴보기 위한 오류 수정 과제로 구분하 여 실시하였다. 확인 과제에서는 오류가 포함된 3 개의 이야기 글을 무작위 순서로 제시하였으며, 아동에게 글을 읽다가 이상한 부분 이 있으면 밑줄을 그어 달라고 요구하였다. 총 18 개의 오류가 포함 
되어 있으며, 아동이 오류를 찾으면 1점, 찾지 못하면 0점으로 채점 하였다. 그 후에 수정 과제를 실시하였으며, 수정 과제는 확인 과제 와 동일한 글이며, 확인 과제의 오류 18 개에 밑줄을 그어 놓았다. 아 동에게 밑줄이 그어진 부분을 적절한 단어로 바꾸어 써 달라고 요 구하였다. 확인 과제와 마찬가지로 아동이 적절하게 수정하면 1점, 적절하게 수정하지 못하면 0점으로 채점하였다.

\section{자료의 통계처리}

모든 통계처리는 SPSS 24.0 프로그램을 사용하여 분석하였다. 언어장애 아동과 일반 아동 집단에 따라 읽기이해 모니터링의 과제 (오류 확인 과제와 오류 수정 과제)에 따라 차이가 있는지를 살펴 보기 위해 두 집단과 이해 모니터링의 과제(오류 확인과 오류 수정) 를 각각 집단 간과 집단 내 독립변수로, 읽기이해 모니터링 점수를 종속변수로 하여 이요인 혼합분산분석(Two-way Mixed-design $\mathrm{ANOVA}$ )을 실시하였다. 또한 오류 확인과 수정의 각 과제에서 각 집단 간에 오류 유형에 따른 차이가 있는지를 살펴보기 위해 이요 인 혼합분산분석(Two-way Mixed-design ANOVA)을 실시하였으 며, 사후분석을 위해 Bonferroni 분석을 실시하였다.

마지막으로 읽기이해 모니터링 능력과 읽기이해와의 관련성을 살펴보기 위해 KOLRA의 읽기이해 원점수와 읽기이해 모니터링의 각 오류 유형 원점수로 Pearson 상관관계 분석을 실시하였다.

\section{연구결과}

\section{두 집단(언어장애/일반)과 과제(오류 확인/오류 수정)에 따른 읽기이해 모니터링}

집단과 과제에 따른 읽기이해 모니터링 점수의 평균과 표준편차 는 Table 2 와 같다. 언어장애 아동은 확인 과제의 이해 모니터링 평 균 점수는 4.80 점 $(\mathrm{SD}=3.02)$, 수정 과제에서는 10.33 점 $(\mathrm{SD}=2.41)$ 이었다. 일반 아동은 확인 과제에서 12.13점 $(\mathrm{SD}=2.29)$, 수정 과제 에서 14.67 점 $(\mathrm{SD}=1.83)$ 이었다. 즉, 언어장애 아동은 일반 아동에 비해 읽기이해 모니터링 능력을 살펴보는 오류 확인 과제와 오류

Table 2. Descriptive statistics (mean and standard deviation) of the comprehension monitoring scores for groups at each phase

\begin{tabular}{lrc}
\hline Group/Task & Detection & Correction \\
\hline LI & $4.80(3.02)$ & $10.33(2.41)$ \\
TD & $12.13(2.29)$ & $14.67(1.83)$ \\
Total & $8.47(4.56)$ & $12.50(3.04)$ \\
\hline
\end{tabular}

Values are presented as mean (SD).

$\mathrm{LI}=$ children with language impairment; $\mathrm{TD}=$ typically developing children.
수정 과제 모두에서 어려움을 보이는 것으로 나타났다.

집단과 이해 모니터링 과제에 따라 읽기이해 모니터링 능력에 차 이가 있는지 살펴보기 위해 이요인 혼합분산분석을 실시한 결과 집단과 읽기이해 모니터링 과제에 따른 상호작용 효과가 나타났다 $\left(F_{(1,28)}=11.023, p=.003\right)$. 또한 집단 $\left(F_{(1,28)}=58.317, p<.001\right)$ 과 과제 $\left(F_{(1,28)}=79.694, p<.001\right)$ 간의 주효과도 나타났다. 언어장애 아동이 일반 아동보다 통계적으로 유의하게 낮은 읽기이해 모니터링 점수 를 보였고, 두 집단 모두 확인 과제가 수정 과제보다 더 어려운 것으 로 나타났다. 특히, 언어장애 아동과 일반 아동과의 이해 모니터링 점수의 차이는 오류 확인 과제에서 더 크고, 오류 수정 과제에서는 줄어들면서 상호작용효과가 나타났다(Figure 1).

\section{오류 확인 과제에서 집단과 오류 유형에 따른 읽기이해 모니터링}

오류 확인 과제에서 집단과 오류 유형에 따른 이해 모니터링 수 행력을 살펴본 기술 통계 결과는 Table 3에 제시하였다. 확인 과제 에서는 집단 $\left(F_{(1,28)}=56.150, p<.001\right)$ 과 오류 유형 $\left(F_{(1,28)}=6.541\right.$, $p=.016$ )에 따라 주 효과가 나타났지만 집단과 오류 유형에 따른 읽 기이해 모니터링 점수의 상호작용 효과는 유의하지 않은 것으로 나 타났다 $\left(F_{(1,28)}=1.946, p=.174\right)$. 오류 유형 간의 차이를 살펴보기 위 해 Bonferroni 사후검정을 실시한 결과 어휘와 외적 비일관성 오류 $(p=.030)$, 어휘와 내적 비일관성 오류 $(p=.016)$, 그리고 외적과 내 적 비일관성 오류 $(p<.001)$ 모두에서 유형 간에 유의한 차이가 있 는 것으로 나타났다.

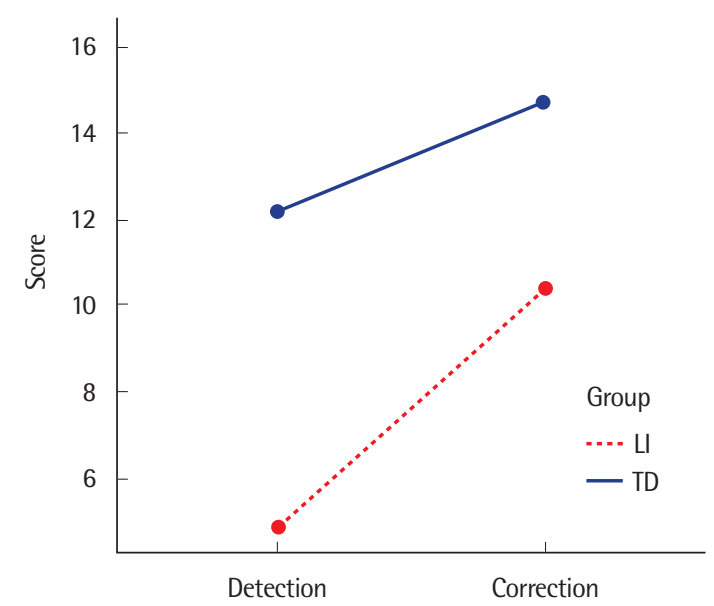

Figure 1. Interaction effect between groups and tasks. $\mathrm{LI}=$ children with language impairment; TD=typically developing children. 
Table 3. Comprehension monitoring scores by error types on the detection task for each group

\begin{tabular}{lcl}
\hline Error type & \multicolumn{1}{c}{$\mathrm{LI}$} & \multicolumn{1}{c}{ TD } \\
\hline Lexical error & $1.40(1.29)$ & $4.33(1.23)$ \\
External error & $2.33(1.39)$ & $4.67(.61)$ \\
Internal error & $1.07(1.10)$ & $3.20(1.74)$ \\
\hline
\end{tabular}

Values are presented as mean (SD).

$\mathrm{LI}=$ children with language impairment; $\mathrm{TD}=$ typically developing children .

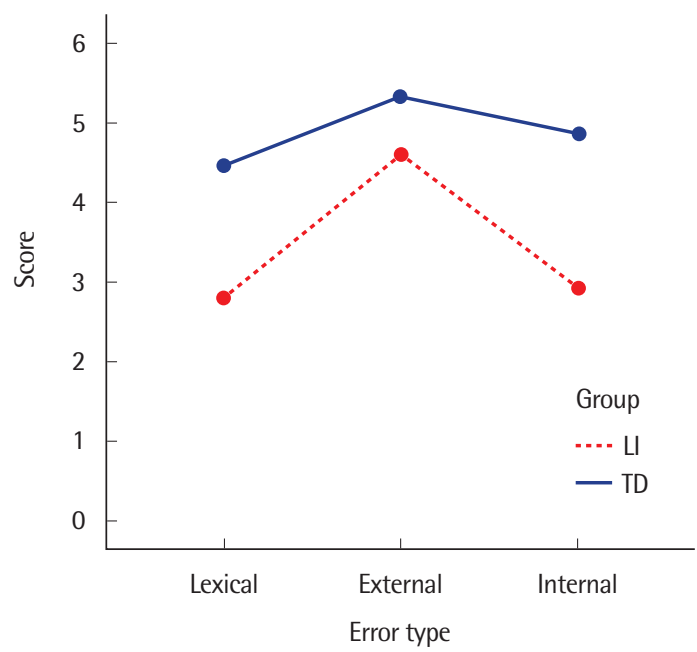

Figure 2. Interaction effect between groups and error types in the error correction tasks. $\mathrm{LI}=$ children with language impairment; $T D=$ typically developing children.

\section{오류 수정 과제에서 집단과 오류 유형에 따른 읽기이해 모니터링}

오류 수정 과제에서 집단과 오류 유형에 따른 이해 모니터링 수 행력을 살펴본 기술 통계 결과는 Table 4에 제시하였다. 수정 과제 에서는 집단 $\left(F_{(1,28)}=30.648, p<.001\right)$ 과 오류 유형 $\left(F_{(1,28)}=32.028\right.$, $p<.001)$ 에 따라주 효과가 나타났으며, 집단과 오류 유형에 따른 읽 기이해 모니터링 점수의 상호작용 효과도 나타났다 $\left(F_{(1,28)}=6.3276\right.$, $p=.018)$. 언어장애 아동은 일반 아동보다 오류를 수정하는 데 어 려움을 보였는데, 특히 어휘 비일관성 오류와 내적 비일관성 오류 를 수정하는데 더 어려움을 보이며 상호작용효과가 나타났다(Figure 2). 오류 유형에 따른 차이를 살펴보기 위해 Bonferroni 사후검 정을 실시한 결과 어휘 비일관성 오류와 외적 비일관성 오류 $(p<.001)$, 외적 비일관성 오류와 내적 비일관성 오류 간 $(p<.001)$ 에 통계적으로 유의한 차이가 있는 것으로 나타났다. 반면 어휘 비 일관성과 내적 비일관성 오류 간에는 통계적으로 유의한 차이가 없는 것으로 나타났다 $(p=.415)$.
Table 4. Comprehension monitoring scores by error types on the correction task for each group

\begin{tabular}{lll}
\hline Error type & \multicolumn{1}{c}{ LI } & \multicolumn{1}{c}{ TD } \\
\hline Lexical error & $2.80(1.52)$ & $4.47(1.18)$ \\
External error & $4.60(.82)$ & $5.33(.72)$ \\
Internal error & $2.93(1.48)$ & $4.87(.91)$ \\
\hline
\end{tabular}

Values are presented as mean (SD).

$\mathrm{LI}=$ children with language impairment; $\mathrm{TD}=$ typically developing children.

Table 5. Correlation between reading comprehension and comprehension monitoring for each group

\begin{tabular}{lcccccc}
\hline & & RC & $\begin{array}{c}\text { Total scores } \\
\text { of CM }\end{array}$ & $\begin{array}{c}\text { Lexical } \\
\text { error }\end{array}$ & $\begin{array}{c}\text { External } \\
\text { error }\end{array}$ & $\begin{array}{c}\text { Internal } \\
\text { error }\end{array}$ \\
\hline Children with LI & RC & 1 & $.650^{* *}$ & $.681^{* *}$ & .330 & .357 \\
Children with TD & RC & 1 & $.754^{* *}$ & .366 & .397 & $.672^{* *}$ \\
\hline
\end{tabular}

$\mathrm{RC}=$ Reading comprehension score of $\mathrm{KORLA} ; \mathrm{CM}=$ Comprehension monitoring; $\mathrm{LI}=$ children with language impairment; $\mathrm{TD}=$ typically developing children. ${ }^{* *} p<.01$.

\section{읽기이해와 읽기이해 모니터링 능력 간의 상관관계}

읽기이해 능력과 읽기이해 모니터링 능력 간의 관련성을 살펴보 고자 읽기이해 검사를 실시한 결과 언어장애 아동은 6.26점 ( $\mathrm{SD}=4.26)$, 일반 아동은 12.46 점 $(\mathrm{SD}=3.44)$ 으로 두 집단 간 읽기 이해 점수는 통계적으로 유의한 차이가 있는 것으로 나타났다 $(t=4.581, p<.001)$. 이후 Pearson 상관분석을 실시하여 KOLRA 원 점수를 사용한 읽기이해 능력과 이해 모니터링 능력(확인과 수정 의 총점), 오류 유형 별 오류 확인과 수정 과제의 총점(어휘, 외적, 내 적 비일관성 오류) 간의 관련성을 살펴보았다. 그 결과, 언어장애 아 동에서는 오류 유형의 총점과 어휘 비일관성 오류가 읽기이해와 상 관관계가 있는 것으로 나타난 반면, 일반 아동 집단에서는 오류 유 형의 총점과 내적 비일관성 오류가 읽기이해와 상관관계가 있는 것 으로 나타났으며 결과는 Table 5에 제시하였다.

\section{논의 및 결론}

본 연구는 초등 3-5학년 언어장애 아동을 대상으로 읽기이해 모 니터링 능력을 살펴보았으며, 읽기이해 모니터링과 읽기이해의 관 련성도 함께 살펴보고자 하였다. 읽기이해 모니터링 능력은 글에 의도적으로 오류를 포함하고, 글의 흐름을 방해하는 오류를 찾는 확인 과제와 이를 글의 흐름에 적절하도록 수정하는 수정 과제로 살펴보았다. 오류 유형은 선행연구에 근거하여 어휘, 외적, 내적 비 일관성 오류를 포함하였다.

연구결과 첫째, 언어장애 아동은 이야기글에 포함된 오류를 확 
인하고 수정하는 데 일반 아동보다 유의하게 낮은 수행력을 보이는 것으로 나타났다. 이러한 결과는 언어장애 아동의 구어이해 모니터 링을 살펴본 이전의 선행연구들과 일치하는 결과로서(Kim, 2004; Jeong, 2010) 언어장애 아동은 글을 읽으며 이해를 방해하는 부분 을 찾고, 이를 해결하기 위해 다양한 이해 전략을 사용하는 데 어려 움이 있다는 것을 보여준다. 언어장애 아동은 읽은 것을 이해하는 과정에서 표면적 수준에서의 어휘와 문법 및 구문 뿐 아니라 텍스 트 수준의 추론 과정에서 일반 아동에 비해 어려움이 있고, 이러한 취약점이 읽기이해에 영향을 미친다고 보고되었는데, 본 연구를 통 해서는 취약한 이해 모니터링 과정도 읽기이해에 부정적인 영향을 미치는 것을 확인할 수 있었다.

언어장애 아동과 일반 아동 집단 모두 오류를 찾는 확인 과제에 서 오류를 수정하는 과제보다 더 어려움을 경험하는 것으로 나타 났다. 이전의 모니터링 연구들은 의도적으로 포함된 오류를 찾고, 아동이 찾은 오류에 한해서 오류가 왜 이상한지를 설명하거나 적절 하게 수정하도록 요구하는 과제를 실시하였기 때문에 아동들이 가 지고 있는 수정 능력이 과소평가되는 경향이 있었다. 본 연구에서 는 아동이 처음에 글을 읽으면서 자발적으로 오류로 인식하지 못 했더라도 명시적으로 오류를 제시하고 그 오류를 의미적으로 적절 하게 수정할 수 있는지를 살펴보고자 하였다. 이는 Paris와 Myers (1981)가 제시했던 이해 전략을 선택하고 적용하는 이해 모니터링 계획(planning)과 조정 단계(regulation)의 수행력을 구체적으로 보고자 한 것이다. 연구결과 두 집단 모두의 아동들은 자발적으로 오류를 찾지는 못하더라도 오류를 명시적으로 제시할 때에는 적절 한 전략을 사용하여 수정하는 것으로 나타나 확인 과정에서의 어 려움이 이해 모니터링을 더 방해하는 요인인 것으로 해석할 수 있 었다. 오류를 확인하는 과제와 수정하는 과제에서의 수행력 차이 는 확인 과제가 더 높은 수준의 상위인지 처리 과정과 관련되어 있 다는 것으로 설명할 수 있을 것이다. Pereira-Laird와 Deane (1997) 에서도 글을 읽는 동안 의미적으로 이상하거나 자신이 이해하지 못한 것을 파악하는 평가 단계(evaluation)가 좀 더 높은 수준의 상 위인지 처리 과정을 필요로 하며, 이렇게 이해를 방해하는 부분을 찾은 뒤 의미적으로 적절한 내용으로 수정하기 위한 전략을 찾고 적용하는 과정은 그 보다는 단순한 인지 처리 과정으로 간주하면 서 오류를 확인하는 단계가 더 어렵다고 해석하였다.

오류 확인 과제에서 사용한 동일한 이야기를 수정 과제에서 다 시 제시하면서 나타날 수 있는 연습효과를 고려하더라도 각 집단 내에서 확인과 수정 과제의 점수 차이는 명확하게 드러났다. 일반 아동들은 오류 확인 과제 $(\mathrm{M}=12.13)$ 와 수정 과제 $(\mathrm{M}=14.67)$ 의 평 균 점수의 차이가 크지 않았던 반면, 언어장애 집단은 오류 확인 과
제 $(\mathrm{M}=4.80)$ 와 수정 과제 $(\mathrm{M}=10.33)$ 의 평균 점수의 차이가 크게 나타나면서 집단과 과제 간의 상호작용 효과가 나타났다. 이러한 차이는 언어장애 아동이 과제에 포함된 오류를 인식하고, 어휘 및 문장들을 유기적으로 연결하여 글의 전반적인 내용을 이해하기 위 해 자신의 이해 정도를 지속적으로 추적하는 데 더 큰 어려움이 있 음을 의미한다. 또한 학령기 언어장애 아동들이 성장하는 동안 의 사를 표현하거나 질문에 대답을 해야 하는 다양한 상황에서 적절 하게 반응하지 못한 경험들로 인해 소극적인 학습자가 되었기 때문 에 나타난 것으로 해석할 수 있다. 이는 Bos와 Filip (1984)의 연구 에서도 유사한 연구결과를 확인할 수 있었다. 위의 연구에서는 학 습장애 아동과 일반 아동을 대상으로 아동이 글 속에 포함된 오류 를 스스로 찾을 수 있는지를 보는 자발적 조건과 자발적으로 이해 를 어렵게 하는 부분을 찾지 못했을 때 연구자가 단서를 제시하는 단서 제시 조건으로 나누어 살펴보았다. 연구 결과 학습장애 아동 은 자발적으로 오류를 찾는 전략을 사용하지는 못했지만, 단서를 제공했을 때에는 오류를 찾을 수 있는 것으로 나타났다. 이에 대해 연구자들은 학습장애 아동들은 소극적인 학습자이기 때문에 글 을 비판적으로 살펴보는 데 적극적이지 못하고, 자신의 이야기 이 해 능력에 대한 자신감이 부족하기 때문에 나타난 것이라고 설명하 였다. 선행연구와 본 연구 결과를 종합하면, 학령기 언어장애 아동 과 학습장애 아동은 이해 모니터링 과정에서 자발적으로 전략을 사용하는 단계에 어려움을 보이고, 그래서 자신이 사용할 수 있는 전략을 가지고 있더라도 전략을 사용할 기회를 얻지 못하기 때문 에 읽기이해에 어려움이 나타난다고 해석할 수 있을 것이다.

두 번째로 언어장애 아동은 일반 아동보다 세 오류 유형 모두를 확인하고 수정하는 데 어려움을 보이는 것으로 나타났다. 오류 유 형을 살펴보면, 오류 확인 과제에서는 두 집단 모두 외적 비일관성 오류를 가장 잘 찾을 수 있었으며, 그 다음은 어휘 비일관성 오류였 으며, 내적 비일관성 오류를 찾는 데 가장 어려움을 보이는 것으로 나타났다. 오류 수정 과제에서도 언어장애 집단과 일반 아동 집단 은 동일한 패턴을 보였다. 두 집단은 외적 비일관성, 내적 비일관성, 그리고 어휘 비일관성 오류 순으로 어휘 비일관성 오류유형을 수정 하는데 가장 어려움이 큰 것으로 나타났다.

확인 과제에서 내적 비일관성 오류를 찾는 것이 가장 어려웠던 이유는 내적 비일관성 오류 유형은 글의 앞 문장에서 제시된 내용 을 기억하고 있다가 글을 읽으며 새롭게 들어온 정보를 통합하고 비교하는 작업기억 능력이 요구되는 과정이기 때문인 것으로 해석 할 수 있다(Baker, 1984; Oakhill et al., 2005). 반면 가장 쉽게 찾았 던 외적 비일관성 오류는 독자가 가지고 있는 배경지식에 어긋나는 정보로, 본 연구에서는 특히 의미적 속성이 뚜렷한 어휘(토끼, 개 
미, 여름 등)들을 사용하였기 때문에 아동이 쉽게 오류를 찾았던 것으로 파악된다. 일반적으로 언어장애 아동의 어휘량이 일반 아 동에 비해 적은 것을 고려한다면 언어장애 아동의 어휘 비일관성 오류의 확인 및 수정이 어려운 것은 예측가능한 결과일 것이다. 수 정 과제에서는 확인 과제와 달리 집단과 오류 유형 간에 상호작용 효과가 있었다. 이는 외적 비일관성 오류보다 어휘와 내적 비일관성 오류 유형을 수정하는 데 언어장애 아동 집단이 더 큰 어려움을 보 이면서 이러한 상호작용효과가 나타났다. 두 집단은 확인 과제와 유사하게 외적 비일관성 오류를 가장 잘 수행하였으나 수정하는 데 가장 어려움을 보인 오류 유형은 어휘 비일관성인 것으로 일관 되게 나타났다. 어휘 비일관성 오류는 무의미 단어인데, 이를 수정 하기 위해서는 독자가 가지고 있는 어휘지식을 활용하여 오류를 찾 은 뒤 무의미 단어를 의미에 적절하게 수정하기 위해 추론 능력이 필요하다. 예를 들어 본 연구과제에 포함된 문장을 살펴보면 '행기 쭉에 있는 소년과 강아지는'의 ‘행기쭉'이라는 무의미 단어가 어휘 비일관성 오류에 해당하며 이러한 오류를 수정할 때, 글의 흐름상 소년과 강아지가 목욕을 하고 있었기 때문에 '욕실' , 화장실' '목욕 탕' 등에 있을 것이라고 추론하여야 한다. 즉, 어휘 비일관성 오류 유형은 앞 문장의 내용을 기억, 통합하고 추론해서 수정해야 하기 때문에 작업기억 능력 뿐 아니라 추론 능력까지 요구되는 오류 유 형으로 볼 수 있다. 특히, 언어장애 아동의 추론 능력 결함(Bishop \& Adams, 1992; Crais \& Chapman, 1987; Weismer, 1985)이 어휘 비일관성 오류를 수정하는데 더 어려움을 야기한 것으로 생각된 다. 내적 비일관성 오류 유형 역시 어휘 비일관성과 마찬가지로 수 정하는 데 어려운 과제인 것으로 나타났다. 내적 비일관성 오류는 대부분의 이해 모니터링 연구에서 사용하는 주요 오류 유형으로, 글의 내용에 서로 일치하지 않는 부분을 포함한 오류 유형이다. 선 행연구에서도 보고했듯이 이해 모니터링을 하기 위해서는 작업기 억 능력이 필수적이며, 특히 내적 비일관성 오류는 작업기억 능력 을 통해 이해 모니터링 전략을 적절하게 사용할 수 있는지를 파악 할 수 있는 오류 유형이다(Baker \& Anderson, 1982; Baker, 1984; Kim, 2014; Kim \& Kim, 2006; Jeong, 2010; Nam, 2007; Oakhill et al., 2005; Song, 1998). 작업기억은 다양한 인지적 과제를 수행하는 동안 입력되는 정보들을 일시적으로 저장하고 조작하는 체계를 말 한다(Cowan, 1998). 언어장애 아동은 이러한 작업기억 능력에서의 어려움이 있다고 보고되어 왔다(Bishop, Norht, \& Donlan, 1996; Gathercole \& Baddeley, 1990). 본 연구에서는 작업기억 능력을 따 로 측정하지는 않았지만 선행연구를 통해 언어장애 아동의 작업기 억 능력 결함이 보고되었기 때문에 이러한 취약한 작업기억 능력 이 이해 모니터링에 영향을 미친 것으로 설명할 수 있을 것이다.
마지막으로 읽기이해 점수와 읽기이해 모니터링 점수 사이의 상 관관계를 살펴보았을 때 두 집단 모두 읽기이해 점수와 읽기이해 모 니터링 총점 사이에서 상관관계가 나타났다. 이러한 연구 결과는 읽기이해부진과 정상발달 아동들을 대상으로 한 Oakhill 등 (2005)과 읽기이해 능력을 예측하는 요인을 연구한 Kim (2014)의 연구결과와 일치하는 결과이다. 즉 읽기부진 아동들 뿐만 아니라 언어장애 아동들의 읽기이해 능력에도 읽기이해 모니터링 능력이 중요한 요인으로 작용한다고 설명할 수 있을 것이다. 본 연구에서 는 집단에 따라 읽기이해 능력과 관련이 있는 이해 모니터링 오류 유형이 다른 것으로 나타났다. 언어장애 아동의 읽기이해 능력은 어휘 비일관성 오류 유형과 상관이 나타났으며, 일반 아동은 내적 비일관성 오류 유형이 읽기이해와 상관이 있는 것으로 나타났다. 이러한 결과는 Kintsch (1998)의 통합 구성 모델로서 설명할 수 있 는데, 이 모델에 따르면 첫 번째 단계는 어휘와 구문 수준이었고 두 번째 단계는 담화 수준에서의 정신적 표상이 이해를 돕는다고 하 였다. 언어장애 아동은 아직 어휘와 구문을 읽고 이해하는 표면적 수준에서의 읽기이해 과정에 있기 때문에 어휘 능력과 같은 요인이 읽기이해와 높은 관련성이 있다고 설명할 수 있다. 반면, 3-5학년 시 기의 일반 아동은 표면적 수준을 넘어 정보를 유기적으로 응집력 있게 통합하는 담화 수준의 이해에 있기 때문에 전반적인 내용의 통합과 관련이 있는 내적 비일관성 오류와 읽기이해가 더 높은 관 련성이 있는 것으로 나타났다고 해석할 수 있을 것이다.

본 연구결과를 종합하면 언어장애 아동은 일반 아동과 비교하 여 담화를 읽고 이해하는 과정에서 오류를 확인하고 수정하는 능 력 모두에서 어려움을 보이는 것으로 나타났다. 특히, 언어장애 아 동들은 오류를 문맥에 맞게 수정하는 것보다 오류를 찾는데 더 어 려움이 큰 것으로 나타났다. 즉, 이해를 방해하는 부분을 찾는 데 는 어려움을 보이지만 그것을 명시적으로 언급했을 때에는 이해가 가능하도록 적절한 전략을 사용할 수 있는 것으로 나타났다. 또한 두 집단 모두 작업기억을 통해 내용을 통합하는 내적 비일관성 오 류에서 가장 어려움을 보이는 것으로 나타났다. 이러한 이해 모니 터링 능력은 두 집단 모두에서 읽기이해와도 높은 관련성을 가지는 것으로 나타났다.

이해 모니터링 과정은 일련의 연속선상에 있는 과정으로 독자가 글을 읽다가 이해를 방해하는 부분을 찾는 평가 단계를 거친 이후 에 다양한 전략을 통해 이해를 방해하는 부분을 수정해야 한다. 본 연구결과를 통해 언어장애 아동은 읽기이해 모니터링에 어려움이 있는 것을 확인하였으며, 읽기이해 모니터링 능력이 읽기이해에 부 정적으로 영향을 미칠 수 있음을 예측할 수 있었다. 이는 언어장애 아동의 읽기이해 평가에서 읽기이해 능력과 함께 읽기이해 모니터 
링 능력도 평가에 포함되어야 함을 시사한다. 뿐만 아니라 이해 모 니터링의 평가 결과를 토대로 아동이 글을 읽는 동안 의식적으로 글 속의 앞 뒤 문장을 연결하고 이해를 방해하는 요인을 찾으며, 방 해하는 요인을 해결하기 위해 사용해야 할 다양한 전략을 함께 중 재할 필요가 있음을 보여주는 결과이다. 본 연구에서는 읽기이해 모니터링에 영향을 미치는 어휘지식, 배경지식이나 작업기억 등은 연구과제에 포함하지 않은 제한점을 가지고 있다. 추후연구에서는 이러한 변인과 읽기이해 모니터링, 읽기이해를 함께 살펴본다면 좀 더 구체적으로 읽기이해 모니터링 과정과 특성을 확인할 수 있을 것이다.

\section{REFERENCES}

Baker, L. (1984). Children's effective use of multiple standards for evaluating their comprehension. Journal of Educational Psychology, 76(4), 588-597.

Baker, L., \& Anderson, R. I. (1982). Effects of inconsistent information on text processing: evidence for comprehension monitoring. Reading Research Quarterly, 17(2), 281-294.

Bishop, D. V. M., \& Adams, C. (1992). Comprehension problems in children with specific language impairment: literal and inferential meaning. Journal of Speech and Hearing Research, 35(1), 119-129.

Bishop, D. B. M., North, T., \& Donlan, C. (1996). Nonword repetition as a behavioral marker for inherited language impairment: evidence from a twin study. Journal of Child Psychology and Psychiatry, 37(4), 391-403.

Bos, C. S., \& Filip, D. (1984). Comprehension monitoring in learning disabled and average students. Journal of Learning Disabilities, 17(4), 229233.

Catts, H. W. (1993). The relationship between speech-language impairments and reading disabilities. Journal of Speech and Hearing Research, 36(5), 948-958.

Chall, J. (1983). Stages of reading development. New York, NY: McGraw-Hll. Cowan, N. (1998). Short-term memory, working memory, and their importance in language processing. Topics in Language Disorders, 17(1), 1-18.

Crais, E. R., \& Chapman, R. S. (1987). Story recall and inferencing skills in language learning-disabled and nondisabled children. Journal of Speech and Hearing Disorders, 52(1), 50-55.

Flavell, J. H. (1979). Metacognition and cognitive monitoring: a new area of cognitive developmental inquiry. American Psychologist, 34(10), 906-911.

Garner, R., \& Reis, R. (1981). Monitoring and resolving comprehension obstacles: an investigation of spontaneous text lookbacks among upper- grade good and poor comprehenders. Reading Research Quarterly, 16(4), 569-582.

Gathercole, S. E., \& Baddeley, A. D. (1990). Phonological memory deficits in language disordered children: is there a causal connection?. Journal of Memory and Language, 29(3), 336-360.

Jeong, S. H. (2010). Comparison of Comprehension monitoring within the context of inference error between language learning disabled children and nonlanguage learning disabled peers (Master's thesis). Ewha Womans University, Seoul, Korea.

Kim, A. H., \& Kim U. J. (2006). Comprehension monitoring and reading comprehension in low-achieving students and normally-achieving students. Journal of Special Education: Theory and Practice, 7(4), 101-119.

Kim, J. M. (2004). Comprehension monitoring of school-age children with specific language impairment. The Korean Society Of Phonetic Sciences And Speech Technology, 51(8), 57-69.

Kim, K. H. (2003). Vocabulary for Korean language education by grade. Seoul: Bagijeong.

Kim, K. S. (2014). The relation between reading comprehension monitoring and reading comprehension of low achieving students. Korean Association for Learner Centered Curriculum and Instruction, 14(11), 221-238.

Kim, K. S., \& Kim, D. I. (2014). The characteristics of meta-cognitive reading strategies of students at risk for reading disabilities. Journal of Special Education: Theory and Practice, 15(3), 321-338.

Kim, W. S., Kim, Y. T. (2006). Variables related to the word recognition and reading comprehension of Korean children with specific language impairment. Korean Journal of Communication \& Disorders, 11(3). 47-63.

Kintsch, W. (1998). Comprehension: a paradigm for cognition. New York: Cambridge University Press.

Lee, Y., Heo, H., \& Jang, S. (2015). Language Scale for School-aged Children (LSSC). Seoul: Hakjisa.

Leicester, H. (2015). Pookins gets her way. Houghton Mifflin Harcourt.

Mayer, M., \& Mayer, M. (1992). A boy, a dog, a frog and a friend. Houghton Mifflin.

Nam, Y. J. (2007). Reading comprehension monitoring in children with attention deficit hyperactivity disorder (ADHD) (Master's thesis). Dankook University, Seoul, Korea.

Oakhill, J., Cain, K., \& Elbro, C. (2014). Understanding and teaching reading comprehension: a handbook. Routledge, London.

Oakhill, J., Hartt, J., \& Samols, D. (2005). Levels of comprehension monitoring and working memory in good and poor comprehenders. Reading and 
Minyoung Park, et al. • Reading comprehension monitoring in school-aged children with LI

Writing, 18(7), 657-686

Pae, S., Kim, M., Yoon, H., \& Jang, S. (2015). Korean Language-based Reading Assessment (KOLRA). Seoul: Hakjisa.

Paris, S. G., \& Myers, M. (1981). Comprehension monitoring, memory, and study strategies of good and poor readers. Journal of reading Behavior, 13(1), 5-22.

Paris, S., \& Oka, E. (1989). Strategies for comprehending text and coping with reading difficulties. Remedial and Special Education, 12(1), 32-43.

Park, H. W. (2014). Korean version of Comprehensive Test of Nonverbal Intelligence-second edition (K-CTONI-2). Seoul: Mindpress.

Pereira-Laird, J. A., \& Deane, F. P. (1997). Development and validation of a self-report measure of reading strategy use. Reding Psychology: An International Quarterly, 18(3), 185-235.
Shin, J. Y. (2008). Phoneme and syllable frequencies of Korean based on the analysis of spontaneous speech data. Korean Journal of Communication Disorders, 13(2), 477-502.

Song, Y. J. (1998). Study of children's comprehension monitoring ability: monitoring standards preference and relationship with working memory capacity. Korean Journal of Child Studies, 19(1), 117-129.

Weismer, S. E. (1985). Constructive comprehension abilities exhibited by language-disordered children. Journal of Speech, Language, and Hearing Research, 28(2), 175-184.

Werfel, K., \& Krimm, H. (2017). A preliminary comparison of reading subtypes in a clinical samples of children with specific language impairment. Journal of Speech, Language, and Hearing Research, 60(9), 2680-2686. 
Appendix 1. Example of narrative text and error types

\section{제목: 꾀돌이 보람이}

옛날 단풍마을에 다리가 불편한 보람이라는 다람쥐가 살고 있었습니다. 보람이는 추운 여름(외적 비일관성)을 준비하기 위해 도토리, 밤송이, 낙엽을 찾아다니고 있었습니다. 보람이가 밤을 발견하고 주우려는데 같은 마을에 살고 있는 날쌘이가 왔습니다. 날쌘이는 단풍마을에서 가장 빠른 다람쥐입니다. "다람쥐가 왜 이렇 게 느리니? 너는 느릿느릿 토끼(외적 비일관성)같아!” 날쌘이는 보람이에게 이렇게 말하고 보람이의 밤송이를 가지고 도망갔습니다. 보람이는 기분이 나빴지만 불 편한 다리 때문에 날쌘이를 잡으러 갈 수가 없었습니다. 나둑(어휘 비일관성)이가 추워지자 배고픈 늑대가 단풍마을에 먹을 것을 찾으러 왔습니다. 늑대는 노래를 부르며 집에 가고 있던 가장 느린 날쌘이(내적 비일관성)를 발견하고 날쌘이를 잡았습니다. 


\section{국문초록}

\section{학령기 언어장애 아동의 읽기이해 모니터링}

박민영 · 윤효진

조선대학교 언어치료학과

배경 및 목적: 본 연구는 학령기 언어장애 아동에게 글자료를 제시하고 글에 포함된 오류 유형을 확인하고 수정할 수 있는지를 통해 읽 기이해 모니터링 능력을 살펴보았다. 오류 유형은 이해 모니터링 연구에서 대표적으로 사용하고 있는 어휘 비일관성 오류, 외적 비일관 성 오류, 내적 비일관성 오류를 포함하였다. 방법: 초등학교 3-5학년의 일반 아동과 언어장애 아동 각각 15 명씩 총 30 명을 대상으로 3개 의 오류 유형(어휘/외적/내적 비일관성)을 포함한 이야기글 3 개를 읽고 오류를 찾는 확인 과제와 연구자가 명시적으로 표시한 오류를 수정하는 수정 과제를 실시하였다. 결과: 언어장애 아동은 일반 아동에 비해 확인 과제와 수정 과제 모두 어려움을 보였으며, 세 개의 오류 모두에서 낮은 수행력을 보이는 것으로 나타났다. 두 집단 모두 확인 과제에서는 외적 비일관성 오류 유형을 가장 잘 찾았으며 그 다음 어휘, 내적 비일관성 오류 유형 순으로 찾았다. 수정 과제에서는 두 집단 모두 외적 비일관성 오류 유형을 가장 잘 수정하였으며, 그 다음 내적 비일관성, 어휘 순으로 수정하는 것으로 나타났다. 또한, 언어장애 아동은 읽기이해 모니터링 총점과 어휘 비일관성 오류 유 형이 읽기이해 능력과 상관이 나타났으며 일반 아동은 읽기이해 모니터링 총점과 내적 비일관성 오류 유형이 읽기이해와 상관이 있는 것으로 나타났다. 논의 및 결론: 언어장애 아동들은 일반 아동에 비해 읽기이해 모니터링 능력에 어려움이 있는 것으로 나타났다. 이러 한 결과는 학령기 언어장애 아동의 읽기이해 모니터링 어려움이 읽기이해에 부정적으로 영향을 미치는 것으로 해석할 수 있다.

핵심어: 학령기 언어장애, 읽기이해 모니터링, 오류 확인 과제, 오류 수정 과제, 읽기이해

본 연구는 제 1 저자의 석사학위 논문을 수정 및 보완하였음.

이 논문은 조선대학교 학술연구비의 지원을 받아 연구되었음(2020).

\section{참고문헌}

김경선 (2014). 읽기 저성취 아동의 읽기이해점검과 읽기이해와의 관계 분석. 학습자중심교과교육연구, 14, 221-238.

김경선, 김동일 (2014). 읽기장애 위험아동의 초인지 읽기전략사용 특성 분석. 특수교육저널: 이론과실천, 8(4), 655-677. 김광해 (2003). 등급별 국어교육용 어휘. 서울: 박이정.

김애화, 김의정 (2006). 읽기부진학생의 읽기이해점검력 및 읽기이해 특성 연구. 특수교육저널: 이론과 실천, $7(4), 101-119$.

김정미 (2004). 학령기 단순언어장애아동의 이해모니터링 능력. 대한음성학회, 51(8), 57-69.

남윤정 (2007). ADHD 아동의 이해점검 능력. 단국대학교 대학원 석사학위논문.

박혜원 (2014). 한국비언어 지능검사(Korean comprehensive Test of Nonverbal Intelligence-Second Edition, K-CTONI-2). 서울: 마인드프레스. 배소영, 김미배, 윤효진, 장승민 (2015). 한국어 읽기 검사(Korean Language-based Reading Assessment, KOLRA). 서울: 학지사. 송영주 (1998). 아동의 이해점검 능력에 관한 연구: 점검기준의 사용과 작업기억 용량과의 관계에서. 아동학회지, 19(1), 117-129. 신지영 (2008). 성인 자유발화 자료분석을 바탕으로 한 한국어의 음소전이 빈도. 언어청각장애연구, 13(2), 477-502. 이윤경, 허현숙, 장승민 (2014). 학령기 아동 언어 검사(Language Scale for School-aged Children, LSSC). 서울: 학지사. 정선화 (2010). 언어학습장애아동과 일반아동의 이야기 추론 오류 이해점검 능력비교. 이화여자대학교 대학원 석사학위논문.

\section{ORCID}

박민영(제1저자, 대학원생 https://orcid.org/0000-0003-2985-8513); 윤효진(교신저자, 교수 https://orcid.org/0000-0003-0011-2566) 